\title{
FLORES DO SERTÃO: PERFILANDO PROFESSORAS FORMADAS PELA ESCOLA NORMAL DE FEIRA DE SANTANA DE 1930 A 1949
}

\author{
Antonio Roberto Seixas da Cruz ${ }^{1}$ \\ Universidade Estadual de Feira de Santana \\ seixasecruz@uol.com.br \\ Marinalva Lopes Ribeiro ${ }^{2}$ \\ Universidade Estadual de Feira de Santana \\ Marinalva_biodanza@hotmail.com
}

\section{RESUMO:}

O presente artigo busca traçar a ideia que as professoras formadas pela Escola Normal de Feira de Santana, entre 1930 e 1949, tinham de si mesmas ao se formarem, e o que pensavam ser necessário ao exercício da docência. Trata-se dos resultados de uma investigação pautada na abordagem qualitativa da pesquisa e em princípios da História Cultural (PESAVENTO, 2005). Este texto foi elaborado a partir do que as normalistas escreviam, umas sobre as outras, nos perfis, documentos publicados no Jornal Folha do Norte, semanário da Cidade de Feira de Santana - Bahia, na ocasião da formatura no Curso Normal. Foram utilizadas, também, como fontes: documentos da própria Escola Normal em estudo e entrevistas com suas ex-alunas, formadas no período supracitado. Ao término da pesquisa, percebe-se que nos "retratos" que faziam de si, as egressas destacavam os atributos físicos, o comportamento moral e profissional esperado da mulher/professora. Entre as características mais destacadas, encontra-se a fragilidade. No entanto, o que se percebe é que essas mulheres foram destemidas e fortes, capazes de se embrenhar nos sertões baianos, sem a companhia dos pais ou responsáveis, no intuito de realizar o que elas mesmas denominavam de missão: levar saber às crianças de todos os recantos sertanejos da Bahia.

Palavras-chave: Educação. Gênero. Formação de Professoras.

\section{SERTÃO'S FLOWERS: DRAWING THE OUTLINE OF TEACHERS GRADUATED FROM THE NORMAL SCHOOL OF FEIRA DE SANTANA BETWEEN 1930 TO 1949.}

\begin{abstract}
:
This article tries to present the idea that the graduated teachers from the Escola Normal of Feira de Santana had of themselves at the time of their graduation during the period 19301949. The objective is to do a reading about how these future teachers thought of themselves, how they related with other people and the world, specially as being a professor. It is a qualitative research based in the principles of Cultural History (PESAVENTO, 2005). The text was constructed based on information collected in reports published in the weekly newspaper of Feira de Santana - Jornal Folha do Norte, where they narrated what they thought about their schoolmates and themselves as well as the profile of being a teacher at the time of their graduation. Information was also collected from school's documents which related interviews with these graduated students. The analyses of theses information revealed what was the "images" they had of themselves as being a teacher and the emphases of their speech was about their physical attributes,
\end{abstract}


moral and professional behavior which showed that it was an expected behavior since they were a woman and teacher. Among the characteristics identified, the most visible one in these ideas is fragility. Therefore, the information also informed that besides all of this, these women were strong enough to be able to go alone to places all over the state of Bahia, leaving behind their homes and parents with the purpose to realize what they called a mission: to take and share the knowledge with children all over of the state of Bahia.

Key words: Education. Gender. Training of teachers.

\section{Introdução}

Neste artigo, traçamos as representações que as formandas da Escola Normal de Feira de Santana, entre 1930 e 1949, tinham de si mesmas no período em que se formaram. Para tanto, tomou-se por base a percepção de que a identidade das pessoas se faz na relação entre o que dizem que elas são e aquilo que elas próprias pensam de si e, a partir daí, colocam-se no mundo e estruturam suas vidas (CIAMPA, 1990).

$\mathrm{Na}$ tessitura deste trabalho utilizamos como fontes jornais da época (1930-1949) e documentos da Escola Normal citada anteriormente. Para isso, partimos de perfis, que se constituíam em descrições das normalistas no último ano do curso de formação para o magistério, feitas pelas companheiras de turma e elaborados no anonimato. Neles, descreviam as colegas, destacando atributos morais, projetos de vida, expectativas quanto ao magistério e convívio com colegas. Neste estudo, trabalhamos com setenta perfis publicados no Jornal Folha do Norte, semanário que circula na cidade de Feira de Santana desde 1909.

As professorandas, nos "retratos" que faziam de si, ressaltavam as qualidades que a mulher deveria apresentar como esposa, mãe e mestra. Entre os atributos apareciam: fragilidade, bondade, humildade, e modéstia. Também evidenciavam habilidades manuais e disposição para servir e sacrificar-se. Eram situações apresentadas como "normais" por fazerem parte, segundo elas, da "natureza" feminina e, portanto, da mãe e da professora. Estes eram os principais atributos considerados importantes na vida das professorandas na sociedade feirense daquele momento histórico e refletiam a concepção de mulher elaborada na sociedade em que viviam e reforçada na formação docente na Escola Normal de Feira de Santana.

Ainda que os perfis tratassem de descrições feitas por adolescentes, povoadas de sonhos e fantasias, as imagens que faziam de si carregavam as marcas deixadas pela cultura que dita, em grande medida, a maneira como os indivíduos devem ou não se comportar na sociedade. Nesse sentido, Geertz (1989, p. 37-38) expõe que:

Assim como a cultura nos modelou como uma espécie única - e sem dúvida ainda nos está modelando - assim também ela nos modela como indivíduos separados. É isso o que temos realmente em comum - nem um ser subcultural imutável, nem um consenso de cruzamento cultural estabelecido.

Dado esses prolegômenos, tomando como pressuposto que as representações expressas nos perfis constituem-se em elementos da identidade das normalistas, 
consideramos importante traçar uma discussão de como se dá o processo de formação da identidade, levando em consideração a categoria gênero. É o que faremos a seguir.

\section{Aspectos históricos sobre a criação e funcionamento da Escola Normal de Feira de Santana}

Com base no perfil da cidade de Feira de Santana, nos anos 20 do século XX, considerada como uma das mais desenvolvidas do interior do Estado da Bahia, o então Governador Francisco Marques de Góes Calmon resolveu destinar-lhe uma Escola Normal, medida que foi publicada no Diário Oficial do Estado da Bahia, de 29 de janeiro de 1926, com o seguinte teor: "O Governador do Estado da Bahia, no uso de sua atribuição resolve localizar uma das escolas normais criadas pela Lei 1.846 de 14 de agosto de 1925, na cidade de Feira de Santana".

Segundo os jornais da época, em especial, o Jornal Folha do Norte, o governo tinha muitos motivos para instalar uma escola normal em Feira de Santana. Em primeiro lugar, estava a importância que essa cidade possuía para as cidades circunvizinhas. Via-se nela, um centro de irradiação comercial e cultural, para onde pessoas, advindas das diversas localidades, acorriam com o intuito de buscar os serviços educacionais inexistentes em seus municípios. Essa realidade pode ser percebida no trecho da reportagem a seguir:

Em contato com as diversas comunas circunjacentes, com as quais se ela mercê de rodovias que da urbis feirense se dispartem ou para ela convergem, cabe-lhe o papel de divulgadora das idéias novas, dos momentosos problemas que agitam os espíritos esclarecidos, entre os quais preeminam os que se relacionam com a instrução popular e, digamos também, o ensino agrícola de par com o cooperativismo de crédito rural (FOLHA DO NORTE, n. 933, p. 1).

Em segundo lugar, dados estatísticos revelavam que parte das escolas rurais que o Estado possuía naquele período estava confiada a leigos, o que representava um obstáculo ao desenvolvimento da educação no Estado da Bahia ${ }^{3}$. Por essa razão, um dos objetivos fundamentais da Escola Normal de Feira de Santana era formar mestras e mestres para alfabetizar as populações rurais do Município e dos municípios circunvizinhos, o que pode ser confirmado no texto abaixo, quando afirma que essa escola consistiria em: “[...] aparelhamento indispensável à derrama de educadores, de que tanto havemos mister para alfabetização das populações rurais que a urbis se vem a tornar centro e núcleo de irradiação intelectual [...] (Folha do Norte, n. 932, p. 1).

Em terceiro lugar, a criação da Escola Normal de Feira de Santana justificava-se pela carência de estabelecimentos de ensino, importantes para a divulgação de conhecimentos imprescindíveis à formação do patriota, comprometida com a defesa e o progresso da nação.

\subsection{A INSTALAÇÃO E FUNCIONAMENTO DA ESCOLA NORMAL DE FEIRA DE SANTANA}

A criação da Escola Normal de Feira de Santana deu-se em 14 de agosto de 1925, sendo inaugurada em $1^{\circ}$ de junho de 1927, passando a funcionar em 10 de junho do mesmo ano. 
A inauguração contou com a presença de autoridades e de diversos setores da sociedade: o representante do titular da Diretoria Geral da Instrução Pública do Estado da Bahia; o corpo docente, já nomeado pelo Governo do Estado; o seu corpo discente selecionado para compor a sua primeira turma (com vinte e uma alunas, e mais dezenove alunos oriundos do extinto Grupo Escolar J.J. Seabra) ${ }^{4}$; do seu corpo administrativo e representantes de outros segmentos da sociedade. O momento inaugural foi festivo, obrigando o fechamento de todo o comércio feirense, assim como das repartições públicas, conforme demonstra uma passagem da Ata da Congregação da Escola Normal, de junho de 1927:

Ao primeiro dia do mês de junho do ano de 1927, nesta cidade da Feira de Santana, no edifício do antigo "Grupo Escolar Dr. J.J. Seabra"5 realizou-se com a maior solenidade o ato da inauguração da Escola Normal da Feira de Santana, uma das criadas pelo Art. 119 da Lei do Ensino em vigor, $\mathrm{n}^{\circ} 1.846$, de 14 de agosto de 1925, localizada nesta cidade por Decreto de 27 de Janeiro de 1926 [...]. ${ }^{6}$

$\mathrm{Na}$ área posterior da Escola Normal funcionava a Escola Anexa de Aplicação, originada da fusão do jardim de infância e das escolas elementares, já existentes em Feira de Santana, conforme explicita o fragmento da Ata de sua Congregação:

[...] Os docentes do curso complementar e escolas primárias do antigo Grupo Escolar Dr. J.J. Seabra, sessões estas que, em virtude da nova organização do estabelecimento, passam a constituir respectivamente o curso fundamental e as escolas de aplicação anexas à Escola Normal da Feira de Santana. ${ }^{7}$

Muitas alunas da Escola Normal fizeram o curso primário ali mesmo, na Escola Anexa à Escola Normal, continuando seus estudos e formando-se em professora.

A Escola Anexa à Escola Normal funcionava como uma escola de aplicação onde as alunas-mestras realizavam suas observações e seus estágios, conforme afirma uma exaluna formada em 1942:

Eu me lembro que comecei na Escola Normal desde o primário, agora que estou me lembrando, porque tinha uma Escola Anexa à Escola Normal. Escola Anexa, e eu praticamente fiz o meu primário lá. As últimas séries do primário eu fiz lá na Escola Normal.. Era uma escola onde os professorandos faziam seu estágio.

Após essa rápida explanação sobre a criação da Escola Normal de Feira de Santana, trataremos da questão da identidade de gênero, categoria indispensável para a compreensão da reflexão feita neste artigo.

\section{Construção da Identidade de Gênero}

É inegável que haja diferenças entre homens e mulheres, biológicas e, também, culturais, estas últimas demarcam, preponderantemente, os papéis que os dois gêneros deverão assumir. Nesse sentido, mecanismos de identificação vão sendo utilizados com a finalidade de "produzir" o homem e a mulher, devendo estes se adequar aos comportamentos que lhes são permitidos, para que possam gozar do status da "normalidade" que sua condição de sexo lhes permite. 
Há uma tendência de explicar as diferenças entre o ser homem e o ser mulher do ponto de vista biológico. É evidente que este tem um papel importante. Contudo, consideramos esse aspecto apenas como ponto de partida para as referidas diferenças, pois, é no contato com a cultura a que pertencem, que homens e mulheres vão agregando às suas identidades, comportamentos ditos masculinos ou femininos (Beouvoir, 1980).

Segundo Grossi (1995),

O processo de constituição de identidade se dá pelo reconhecimento de que existem pessoas idênticas e diferentes de nós mesmos. [...] O gênero se constrói sobre o corpo biológico, que é sexuado. As estruturalistas pensam que só pode haver dois gêneros, uma vez que eles se constituem cognitivamente sobre o corpo sexuado, que é dual (macho e fêmea). A existência de dois gêneros não exclui a possibilidade de que estes sejam constituídos em vários modelos de feminino e de masculino, modelos que variam histórica e culturalmente, mas, também, que têm diferentes matizes no interior de cada cultura.

Assim, as características biológicas são anexadas às culturais, e os conceitos e as crenças determinam o que o homem e a mulher podem ou não fazer, como um e outro devem se comportar. Esses padrões de conduta definirão uma identidade, responsável pela forma como homem e mulher devem se colocar diante das questões que o mundo imediato lhes apresenta e na relação com os outros.

Segundo Saffioti (1987, p. 8):

A identidade social da mulher, assim como a do homem, é construída através da atribuição de distintos papéis, que a sociedade espera ver cumpridos pelas diferentes categorias de sexo. A sociedade delimita, com bastante precisão, os campos em que pode operar a mulher, da mesma forma como escolhe os terrenos em que pode atuar o homem.

Essa concepção não é do domínio geral, de modo que muitos interpretam esse fenômeno social como natural, como se ao homem e à mulher fossem dadas características inatas que, para se apresentarem, precisam apenas da maturação biológica. Sobre isto afirma Saffioti (1987, p. 9):

[...] Há sociedades nas quais a mulher não interrompe suas atividades extralar, inclusive a função da caça, quando tem um filho. Há tribos indígenas brasileiras cujas mulheres, em seguida ao parto, banham-se nas águas de um rio e retomam imediatamente sua labuta. Nestas tribos, cabe ao pai fazer repouso e observar uma dieta alimentar especial. Este costume chama-se couvade.

O recorte acima trata do comportamento de tribos em relação à conduta diante de um parto que se diferencia daquilo que comumente assistimos em nossa sociedade, na qual a mulher é cercada de cuidados quando pare; naquelas tribos as mulheres logo retornam às suas atividades. Assim, percebemos o quanto a cultura é capaz de (re)significar hábitos e atitudes, elaborando diferentes significados para acontecimentos semelhantes.

Um dos principais responsáveis pela naturalização dos papéis do homem e da mulher na sociedade é o processo educativo - ato eminentemente político, comprometido com a formação da personalidade dos sujeitos, responsável por transmitir-lhes valores, impor-lhes proibições, apresentar-lhes e inculcar-lhes modelos com os quais cada um - 
homem ou mulher - deverá se identificar e, consequentemente, aderir, segundo sua "natureza" (BUTLER, 2003).

Assim, homens e mulheres, mesmo ressignificando as injunções culturais, submetem-se, em grande medida, a condicionamentos que lhes são apresentados pela sociedade e reforçados por instituições, em particular a família, a escola e a religião. Nessa trama, os sujeitos vão representando o mundo em que vivem, dando sentido ao outro e aos demais fenômenos existentes. Tal postura, explica-se no campo da teoria das representações sociais, que, segundo Louro (2001), não se interessa em perguntar se determinada representação elaborada 'corresponde' ou não ao 'real', mas, ao invés disso, preocupase em buscar compreender como as representações produzem sentidos, quais seus efeitos sobre os sujeitos, e como constroem 'o real'".

Dessa maneira, aos homens é permitido e exigido, segundo o seu "caráter natural", serem mais fortes, destinados ao sucesso e à liderança. Segundo Stigger e Wenetz (2006, p. $71)$

[...] As habilidades e características de meninos e de meninas não são parte de um processo entendido comumente como natural ou biológico, como também são constituídas por aprendizagens próprias de cada contexto histórico e social. Tais processos de aprendizagem também configuram o recreio escolar como um espaço em que as vivências quotidianas e os sentidos atribuídos a elas, fazem diferença e marcam os corpos para distingui-los, pois definem como se pode ser, o que se deve ou não fazer, de que modos e em que lugar, caracterizando os corpos e gestos de uma maneira em detrimento de outras.

Essas características aparecerão como parte de sua natureza, o que vão colocá-los como mais capazes de transgredir os condicionamentos que lhes são apresentados. Enquanto para as mulheres, consideradas dóceis, frágeis e menos capazes de ousar, os elementos da educação são mais determinantes e cobram delas um comportamento submisso, entendido como constitutivo de sua condição de gênero (SOUSA, 2005).

$\mathrm{Na}$ escola, as diferenças entre homens e mulheres são reforçadas, a exemplo da disciplina: o bom aluno é aquele considerado obediente e acomodado; e o mau é aquele que se comporta de forma contrária. Não obstante, o protótipo do aluno bem comportado vai coincidir com o que se espera das mulheres. Também se atenua a culpa do homem desviante da conduta esperada, afirmando-se que é do caráter masculino a impetuosidade, a desobediência, situação que é interpretada como sinônimo de coragem, criatividade e autonomia, características que lhes são conferidas desde a infância, como se fosse algo inerente (LOURO, 2001).

Estabelece-se, nesses termos, um distanciamento de papéis entre homem e mulher, reforçando diferenças culturalmente produzidas. Assim, com a influência dos responsáveis pela divulgação dos comportamentos socialmente aceitos (os pais, os educadores e os meios de comunicação, entre outros), as pessoas passam a ser:

Classificadas segundo o seu sexo, criando estereótipos que desenvolvem a desigualdade e a discriminação. Através de generalizações forçadas, em que a verdade vai sendo alterada, diferenças vão sendo estabelecidas entre homens e mulheres, tornando seres humanos essencialmente iguais em diferentes (Passos, 1999, p. 94).

Essa divisão sexista terá consequências na vida das pessoas, entre as quais destacamos a construção de uma identidade elaborada a partir de elementos 
predeterminados, que reforçam a crença de que o destino da mulher é ser dócil, frágil, maternal, leal, acolhedora, meiga, entre outras qualidades socialmente apreciadas na sua conduta.

Com isto, estamos dizendo que as diferenças entre homens e mulheres, ganham significado a partir da cultura, ou seja, estamos optando por uma concepção que considera o sujeito como resultado de suas experiências. Essa concepção origina-se da idéia de que o ser humano não é uma entidade abstrata, mas é fruto de sua relação com a natureza e com o meio social, resultado de suas experiências com o mundo concreto. Nesse processo constrói sua identidade, que segundo PASSOS (1999, p. 98):

[...] É a forma dos indivíduos se reconhecerem e de serem reconhecidos, a maneira como se vêem e são vistos. Assim, aquilo que os outros dizem e esperam dele, passa a fazer parte do que ele acha que é a sua natureza e modelará o seu perfil, a sua forma de ser. Isto porque, como indica Ciampa (1989): 'um indivíduo é a pessoa que diz que é e que os outros dizem que é'.

Essa identidade é oriunda de representações coletivas, que alimentam as crenças individuais, mesmo de forma inconsciente, fazendo parte de uma cultura elaborada historicamente. Dessa forma, mesmo recebendo essas influências externas advindas de sua cultura, os indivíduos ressignificam valores e crenças, agregando elementos novos a partir de suas experiências no mundo, o que afasta a possibilidade de torná-lo um sujeito passivo, o que faz da identidade um elemento dinâmico, conforme evidencia Moscovici: "as pessoas e grupos, longe de serem receptores passivos, pensam por si mesmos, produzem e comunicam incessantemente suas próprias e específicas representações" (Moscovici, 2003, p. 45)

Assim, um modelo identificatório depende de uma base conceitual que toma conotação diferenciada a depender da sociedade a que pertence. Os padrões de identidade são diferentes quando são distintos o tempo e o espaço onde se formam e se processam.

Outro elemento a ser destacado na formação da identidade é a dialética existente neste processo, porque é na trama das relações, que ela é constituída, na qual o indivíduo ora se vê como igual ao outro, ora se vê como diferente. Assim, a alteridade é indispensável no processo de identificação, pois é mediante o confronto com o outro que se constitui um modelo a ser seguido ou evitado pelo indivíduo que se forma, ou seja, aponta para um comportamento que define aquilo que se quer ser, parecer ou não.

Para PASSOS (1999) a identidade é um fenômeno dialético, que requer para o seu entendimento o sentido do devir, como processo, pressupondo, todavia, em alguns aspectos permanência e transformação. Para fundamentar seu argumento, a autora toma como exemplo a questão do nome, ou seja, identificam-se as pessoas pelo nome - especialmente o de família - pelo sexo, pela nacionalidade, etc. Esses elementos, ressalta Passos (1999) requerem uma análise que os considere em 'détour', pois se de um lado podem representar atributos afirmativos que valorem o sujeito positivamente, podem, de uma outra forma, ser usados de maneira desqualificadora, e esteriotipada, o que pode se desdobrar em comportamentos de inferiorização do outro, marcando-o, muitas vezes, até o extremo da estigmatizarão.

Os atributos mencionados servem para categorizar as pessoas, dizendo o que elas são e o que lhes é permitido fazer. A partir dessa categorização e da posse da identidade, oriunda dos atributos assumidos pelos indivíduos, estes passam a se perceber de acordo como o espelho social os reflete. Isto porque a subjetividade e o mundo interno do sujeito são, também, formados de signos, de imagens, de metáforas, de emblemas, de mitos e de 
alegorias. Esse mundo é resultado do contato relacional com os outros e é expresso e constituído, também, no campo da linguagem (SCOTT, 1990).

É no contexto da formação da identidade, que se dá a formação da identidade de gênero que, segundo Badinter (1993), situa-se além da diferença de sexo. Pois, enquanto esta tem relação com o fator biológico do indivíduo, a identidade de gênero é proveniente do sentimento de se pertencer a um sexo, construção que se dá no processo de socialização e, portanto, da experiência com o mundo em sua concretude.

A esse respeito, Simone de Beauvoir (1980, p. 73) ressalta que:

A humanidade não é uma espécie animal; é uma realidade histórica. A sociedade humana anti-phisis: ela não sofre passivamente a presença da Natureza, ela a retoma em mãos. Essa retomada de posse não é uma operação interior e subjetiva; efetua-se objetivamente na práxis. Assim, a mulher não poderia ser considerada apenas um organismo sexuado: entre os dados biológicos só tem importância os que assumem, na ação, um valor concreto; a consciência que a mulher adquire de si mesma não é definida unicamente pela sexualidade. Ela reflete uma situação que depende da estrutura econômica da sociedade, estrutura que traduz o grau de evolução técnica a que chegou a humanidade.

Com base nessa concepção, acreditamos que as identidades são constituídas em meio a uma diversidade de comportamentos sociais que, certamente, influenciou na forma de ser das professoras que se formaram na Escola Normal de Feira de Santana, no período tratado por este artigo. A partir desse processo de identificação, passam a ter uma idéia de si mesmas, assumindo como seus, os atributos que lhes eram exigidos pela sociedade a que pertenciam.

A partir desse pressuposto, fizemos uma (re)leitura da imagem que as professorandas faziam da mulher e professoras ao falarem das suas qualidades. Para tal, levamos em consideração a idéia de Pesavento (1995, p.16), quando diz:

A rigor, todas as sociedades, ao longo de sua história, produziram suas próprias representações globais: trata-se da elaboração de um sistema de idéias-imagens de representação coletiva mediante o qual elas se atribuem uma identidade, estabelecem suas divisões, legitima seu poder e concebem modelos para a conduta de seus membros. Seriam pois representações coletivas da realidade, e não reflexos da mesma.

Essas representações faziam com que as normalistas se vissem como figuras meigas, dóceis, frágeis, alegres, bondosas, entre outros comportamentos valorados naquele período e incorporados por elas, como integrantes de sua "natureza" e necessários em suas funções de mães e educadoras.

\section{Valores e atributos destacados nos perfis}

\subsection{FRAGILIDADE}

Era comum as professorandas terem seus perfis publicados em jornais de circulação local, neste caso, no jornal Folha do Norte. Neles eram retratadas como crianças: frágeis, puras, carentes de proteção, como escreveu uma delas no ano de 1933: 
É magrinha, de compleição delicada, possuidora de uns lindos olhinhos castanhos; os seus lábios entreabrem-se para dar passagem a um sorriso franco e leal, deixando a descoberto, os seus dentinhos alvos e pequeninos (Folha do Norte, $\mathrm{n}$. 1275, p.1).

Essas descrições eram colocadas no diminutivo, como se estivessem tratando de criancinhas: olhinhos, narizinho, rostinho. Em primeiro lugar, essa postura pode apontar para um linguajar familiar, próprio do grau de proximidade entre as formandas. Mas, também, pode apontar para uma questão de gênero, que consiste em tratar a mulher como criança e, com isto, tende a colocá-la como incapaz de gerir seu destino, precisando de um tutor.

Nos perfis, a infantilização da mulher é apresentada de forma explícita e como meritória, conforme afirmam os trechos seguintes:

[...] Tem a nossa B. olhos vivos e travessos que deixam bem se ler neles a infantilidade de sua alma. Com seus dezoito anos. Tem ainda nos seus brinquedos a traquinice dos oito anos. Gosto de ver-te assim! Lembras aqueles versos do poeta Casemiro de Abreu, que tinha saudades da sua infância, e tu bem os praticas ainda. É uma alma de criança no corpo de uma jovem (Folha do Norte, n. 1310, p. 1).

Dentre todas as tuas companheiras de série, fui eu que me julguei com mais direito de te traçar as linhas finas de menina bonita(...)

A mim era dado este dever grato amorável, porque ninguém mais do que eu pôde e soube presentear o teu coração, cheio de tantas infantilidades belas.

Não é só belo o teu rostinho heleno, como a tua alma que dorme ainda aos derradeiros sonidos das canções que te embalaram pequenina.

Nos meus pensamentos eu te vejo tão meiga, tão suave e pura, sequiosa de brinquedos, a arrumar bonecas, duvidando que tivesse chegado ao fim de uma carreira em que um ar circunspecto, sério orgulhoso circunda a menina que deseja lhe chamemos de moça, sem esquecer o título dignificante que com garbo conquistou.

Toda a dor se acalma fenece diante do seu risinho de criança da qual nunca se avizinhou a dor (Folha do Norte, n. 1363, p. 1).

Ao se autodenominar como figuras infantis, as professorandas assumiam as injunções sociais que lhes foram imputadas. Considerarem-se pequenas e crianças, poderia significar verem-se como dependentes e incapazes de desempenhar papéis de cidadãs autônomas, livres e capazes de escolher onde gostariam de trabalhar, os lugares que gostariam de visitar, entre outras situações que lhes apresentava o dia-a-dia.

Outro aspecto levantado é a fragilidade, característica que não viam como negativa, a ponto de decantá-la em vários perfis:

Hortênsia cor de rosa esmaecida,

Como um sonho de amor dentro da vida.

É morena, esbelta, simpática, de olhos vivos e expressivos, ostentando lábios delicados e purpurinos. Sua estatura é média; seus cabelos, que formam ondas graciosas, são castanhos e sedosos. Quando os seus lábios se entreabrem num sorriso, parecem ter o brilho de uma manhã primaveril, deixando ver-se a bondade de uma alma pura. Sua voz relembra a voz do rouxinol, que na floresta quebra o silêncio com a sua melodia miraculosa, olhando os raios belíssimos do sol aurifulgente (Folha do Norte, n. 1362, p. 1).

As professorandas, também, eram identificadas como seres bondosos, puros e quase angelicais: 
No jardim florido e perfumado da Escola Normal, ambiente ímpar, no qual a meiguice e a beleza entrelaçadas fizeram o seu ninho mimoso, C. é bem o seu "amor perfeito" e diz na delicadeza do seu andar as palavras cadentes de Mantegazza - olhai para mim; aqui estou! (Folha do Norte, n. 1321, p. 1).

Outro depoimento complementa a idéia de fragilidade:

Simpática, mas de uma simpatia terna e original, delicada qual violeta a esconderse entre folhazinhas verdes, assim é a G. Alva, cabelos castanhos levemente ondulados, com o seu rostinho semelhante a 'lua cheia', ela nos mostra um par de olhos verdes e cismadores que traduzem toda a bondade do seu coração, e toda a brandura da sua alma (Folha do Norte, n. 1313, p. 1).

As normalistas se viam como seres delicados e sensíveis como as flores. Esse entendimento demonstra a visão de mulher, influenciada pelo romantismo que a sociedade vivenciava naquele período, expressado pelos clássicos da literatura brasileira. Tal visão acabou por colocá-las, pelo menos no campo do imaginário, num patamar distante do mundo social. Isto porque, enquanto as mulheres se viam como figuras de ornamentação acreditavam estar no mundo para enfeitá-lo. Assim, entendemos que, ao se perfilarem, destacavam o que acreditavam ser essencial no ser feminino, ressaltando os atributos socialmente valorizados na conduta da mulher na sociedade brasileira, baiana e, especialmente, na feirense.

Nos depoimentos aparecem frases que afirmam ser a mulher "um manancial de ternuras inesgotáveis", com "voz acariciante que enleva", e gestos que deixam "transparecer os reflexos de uma simplicidade natural", "exemplo vivo de candura, de gentileza e polidez". Segundo revelam os perfis analisados, ser uma boa moça significava, antes de tudo, ser delicada, meiga, falar baixo, ter bons modos e nunca expressar insatisfação diante das situações adversas ou demonstrar segurança e independência.

A metáfora da flor tem muitos significados, entre os quais encontra-se aquele que diz que a mulher deve estar enfeitando um ambiente, ser um adorno e não um ser central e atuante. Isto porque às flores, cabe apenas ornamentar sem interferir no caminho que o mundo deve ou não tomar. Imaginar-se como flor pode significar, também, estar à mercê daqueles "jardineiros" que deverão provê-las das coisas necessárias à sua sobrevivência. Isto faz com que se tornem objetos de satisfação dos outros, seres para o outro e não para si.

\subsection{Bondade}

Entre os atributos mencionados nos perfis destaca-se a bondade, posta como indispensável na composição da personalidade de uma mulher que quisesse ser bem aceita socialmente, conforme os excertos abaixo:

Em breve tempo, porém, a convivência escolar mostrou-nos clarividentemente, o quanto de bondade possuía $\mathrm{Z}$. e foi o bastante para que a estimássemos muito e muito (Folha do Norte, n. 1102, p. 2).

[...] Como a humilde violeta que vive ocultada entre as suas folhas, assim vive a minha perfilada; mui retraída e simples, e ocultando sempre toda a sua bondade em uma grande modéstia (Folha do Norte, n. 1365, p. 1).

Ser bondosa era uma qualidade da mulher, de quem se esperava um comportamento solidário aos seus semelhantes. Esse elemento está ligado à função quase sacerdotal que 
deveriam assumir as professorandas, de quem se esperava dedicação à família e aos educandos, colocando em prática o papel materno de nutrir, cuidar e se desvelar. Afinal, ser professora ainda é visto como uma forma de extensão das atividades maternas, e deve ser desempenhada como a maternidade biológica, com devotamento e sacrifícios.

\subsection{Almas angelicais, afeitas aos sacrifícios}

O século XIX representou um período de profundas transformações para o mundo ocidental. Momento histórico no qual as controvérsias e as ambiguidades imperaram, apresentando-se aos olhos dos cientistas como luzes, em meio a tantas descobertas. Entre as controvérsias e as transformações assistidas, temos a mudança do ideário sobre a mulher. Nesse período, existiram diversificadas polêmicas referentes à natureza feminina, e, segundo D'INCAO (1997, p. 223):

A sociedade brasileira sofreu uma série de transformações: a consolidação do capitalismo; o incremento de uma vida urbana que oferecia novas alternativas de convivência social; a ascensão da burguesia e o surgimento de uma nova mentalidade - burguesa - reorganizadora das vivências familiares e domésticas, do tempo e das atividades femininas; e, por que não, a sensibilidade e a forma de pensar o amor.

Até então, o juízo que se fazia sobre a mulher era bastante ligado ao pensamento cristão, que ora a apresentava com um certo grau de santidade, comparando-a à figura de Maria, pura e santa; e ora a apresentava como demônio, atrelando-a à figura bíblica de Eva - lasciva e corruptora. Tal ideário estava ligado aos paradigmas da sexualidade feminina da época.

Não obstante, com o processo de industrialização, a mulher passa a ser utilizada como mão de obra, desempenhando papel importante na produção. Essa inserção fez com que a idéia sobre a mulher como pecadora e diabólica fosse empalidecida. A partir de então, o culto à sua imagem aproxima-se cada vez mais à do ser angelical. Desta forma, a idéia de santificação da mulher toma se fortalece. Isto é percebido nos perfis, portadores de uma mentalidade que enquadrava a mulher num padrão de comportamento nas décadas de trinta e quarenta do século XX.

A maioria dos perfis coloca as mulheres como anjos, figuras de candura e doçura, tal qual se apresentam no imaginário cristão daquele momento:

[...] Aliás, há momentos em que ela deixa transparecer num sorriso branco, a alegria que brinca no seu coração; em outras, porém sem que possamos descobrir a causa, lê-se no seu semblante angélico uma preocupação qualquer que a torna tristonha (Folha do Norte, n. 1103, p. 1).

Quanto à comparação com figuras angelicais, os trechos de outro perfis afirmam:

Possuidora de uma alma angelical ela mostrou-se sempre boa e amável para com os seus colegas [...] A sua cor alva fulge a cor formosa, rosada com que se adornam os anjos no empireu (Folha do Norte, $n^{\circ} 1269$, p. 2).

Em sua alma angélica, prazenteira reina a aurora da poesia, canta o sublime e santo poema da mocidade. Esta garota é dona de umas mãozinhas delicadas que alguém elogiava sempre, pensando no rumo feliz que elas pudessem imprimir no seu 
destino. Possui um riso infantil de criança curiosa (Folha do Norte, n $^{\circ} 1271, \quad$ p. $01)$.

Nos fragmentos transcritos fica evidente que as professorandas se viam como figuras angelicais, incapazes de se colocar no mundo real, como seres históricos e responsáveis pelo seu destino. No imaginário delas, a mulher era uma espécie de santa. Por exemplo, em 1933, a comparação foi feita, aproveitando os versos que Menotti del Picchia fez para sua mãe: "Quem sente a carícia deliciosa do olhar de N., sem se lembrar instintivamente dos adoráveis versos de Menotti del Picchia: 'Tenho uma santa em casa, o seu olhar encanta. O olhar dela é porém, igualzinho ao da santa" (Folha do Norte, n. 1110, p. 1).

O ideal de santidade não estava ligado unicamente à mulher-professora, mas ao ideário que se tinha sobre a mulher, conforme diz D'INCAO (1997, p. 237):

A distribuição de papéis em Esaú e Jacó revela a crescente santificação da mulher como mãe, através do sofrimento, enquanto todos os deveres do pai apontam na direção de ganhar dinheiro para o sustento da família. Pode-se sentir por parte da mulher, o cultivo da domesticidade e dos deveres de ser esposa. Toda fragilidade, e ao mesmo tempo, fortaleza de mãe é sublimada.

Ser santa era uma condição que não combinava com o de ser sujeito ativo, real e histórico. Ao contrário, é uma forma de anular-se enquanto sujeito capaz de decidir sobre o seu próprio destino. Ser considerada santa carregava consigo exigências, entre as quais encontrava-se a idéia de resignação e conformação diante da própria realidade, o que em nossa concepção fortalece a submissão.

\subsection{Resignação, aceitação e sacrifício}

Aos semblantes ditos angelicais, acoplava-se a noção de sacrifício, herdada da ligação do magistério à vida sacerdotal, como se observa a seguir:

Alma afeita ao sacrifício! Não hesita em se sacrificar para servir a alguém. Cumpridora fiel de todos os seus deveres, N. encontra, por certo, na vida alguns espinhos; mas a coroa brilhante que Deus reserva para as almas boas circundará a sua fronte (Folha do Norte, n. 1110, p. 1).

Mesmo não fazendo menção direta ao que se espera da professora, o recorte remete à idéia de que ser mestra era assumir a vida de sacrifícios, como uma "vocação" ou missão, que precisava ser aceita sem lamentações. Nesse caminho, a ajuda divina era fundamental, por considerar que a formação de mulheres esteve historicamente nas mãos de ordens religiosas ou se não o eram, seguiam suas orientações.

Em outros perfis, o sacrifício e a resignação aparecem como importantes na personalidade da mulher: "Jamais ouvimos dos seus lábios uma queixa ou reprovação, distribuindo, parcimoniosamente, atenções e gentilezas" (Folha do Norte, n. 1101, p. 2).

Sobre o mesmo aspecto outra perfiladora afirma:

Como amiga, não se conhece melhor: sincera e fiel, como poucas, isso posso afirmar aos leitores, pois bem conheço U., e a considero como a minha maior 
amiga; mais que amiga, irmã. Sacrifica-se muitas vezes só para ter o prazer de servir a quem quer que seja (Folha do Norte, n. 1365, p. 1).

Esboça-se nesses fragmentos, um caminho que aponta para essas mulheres uma vida de sacrifícios, que engloba aceitação e resignação, qualidades fundamentais na vida da mulher daquela época. A valorização do sacrifício está ligada, possivelmente, a origem do magistério no Brasil, que durante dois séculos (1549-1759) ficou a cargo, principalmente, dos jesuítas, que consideravam as suas missões como verdadeiros sacrifícios. Resquícios dessa mentalidade persistem nos dias atuais e, eram bem mais marcantes, nos anos trinta do século XX, quando a mulher havia se tornado a principal responsável pela educação infantil.

\subsection{Magistério: sacerdócio e maternagem}

O sentimento de vivenciar o magistério como sacerdócio, expressa-se claramente na oração do mestre, de Gabriela Mistral, reveladora do imaginário religiosao, que coloca o magistério como uma espécie de sacerdócio:

Senhor! Tu que me ensinaste, perdoa que eu ensine e que tenha o nome de mestra que tiveste na terra. Dá-me o amor exclusivo de minha escola: que mesmo a ânsia da beleza não seja capaz de roubar minha ternura de todos os instantes. [...] Dá-me que eu seja mais mãe do que as mães, para poder amar e defender, como as mães, o que não é carne da minha carne. Dá-me que eu alcance fazer de uma das minhas discípulas o verso perfeito e deixar gravada na sua alma a minha mais penetrante melodia, que assim há de cantar, quando meus lábios não cantarem mais (apud LOURO, 1997, p. 463).

Essa característica foi mantida com o ingresso das mulheres no magistério, mesmo após as transformações econômico-sociais vividas pelo Brasil como afirma LOURO (1997, p. 450):

[...] A entrada das mulheres nas escolas - ansiosas para ampliar seu universo -, restrito ao lar e à igreja. A partir de então passam a ser associadas ao magistério características tidas como 'tipicamente femininas': paciência, minuciosidade, afetividade, doação. Características que, por usa vez, vão se articular à tradição religiosa da atividade docente, reforçando ainda a idéia de que a docência deve ser percebida mais como um 'sacerdócio' do que como uma profissão [...].

Também as professorandas em estudo relacionavam essa carreira a uma missão divina, vinculada à idéia de que a mulher era talhada especialmente para exercer a função de mestra da primeira infância, visto que, ensinar era atributo considerado, sobretudo, feminino e ligado ao ato de maternar.

Quanto a este aspecto, Louro (1997, p.450) afirma que o discurso da época sobre a função da mulher no magistério afirmava que:

[...] As mulheres tinham 'por natureza', uma inclinação para o trato com as crianças, que elas eram as primeiras e 'naturais educadoras', portanto, nada mais adequado do que lhes confiar a educação escolar dos pequenos. Se o destino primordial da mulher era a maternidade, bastaria pensar que o magistério representava, de certa forma, a extensão da maternidade, cada aluno ou aluna vistos como um filho 'espiritual'. $\mathrm{O}$ argumento parecia perfeito: a docência não subverteria a função feminina fundamental, ao contrário, poderia ampliá-la ou sublimá-la. Para tanto 
seria importante que o magistério fosse também representado como uma atividade de amor, de entrega e doação. A ele acorreriam aquelas que tivessem 'vocação'.

As idéias que aparecem nos perfis, trazem indícios de que o magistério era visto como uma missão "sacerdotal" e exigia entrega e sacrifício. Assim, era considerado como função feminina, de quem se esperava resignação e capacidade de suportar as dores provocadas pelos "espinhos" oferecidos pela carreira de mestra:

Desejo a você, J., que a chuva de rosas, prometida por Santa Terezinha caia sobre sua cabeça, a fim de lhe ensinar a trilha do dever e também dar-lhe a resignação para sofrer os ferimentos produzidos pelos aguçados espinhos que se encontram no roseiral da sublime missão que vai desempenhar: mestra e mãe! (Folha do Norte, n. 1314, p. 1).

É evidente a relação entre os papéis de mãe e mestra, assim como dos sacrifícios que ambos demandam. Os perfis apresentam o magistério como tarefa árdua, exigindo tenacidade e compromisso, inclusive cívico, o que respondia a um dos objetivos da Escola Normal de Feira de Santana, que se harmonizava com os ideais pregados pelos governantes daquele período - a construção de uma identidade nacional, que resguardasse os valores da cultura originalmente brasileira. Como está registrado a seguir:

[...] Agora resta-lhe, somente, entrar nas lindes do magistério e trabalhar ardorosamente pela instrução do torrão que lhe serviu de berço, e, trabalhando assim, pelo desenvolvimento moral e intelectual dos filhos do sertão, presta um grande e inolvidável serviço ao Brasil, sua pátria amada, porque o futuro dos sertões é em grande parte o futuro do Brasil (Folha do Norte, n. 1270).

No seu ideário de mestras, as professorandas demonstravam ser necessária uma luta em favor dos "irmãozinhos" que, segundo elas, encontravam-se nas trevas da ignorância e precisavam da luz do saber. Combatê-la significava viver os riscos de uma batalha que exige sacrifício e doação. Assim, demonstravam disposição para enfrentar as dificuldades:

A vida das ilusões está prestes a findar. Vamos ingressar na realidade, onde tudo é positivo e real e não efêmero. As quimeras e ilusões passaram; e, daqui em diante, os nossos irmãozinhos esperam por nós, para que os tiremos das trevas da ignorância, ensinando-lhes tudo que é belo, tudo que é grandioso - amar e servir nossa Pátria! Eu tenho a esperança que você há de combater pelo mesmo ideal pelo qual os brasileiros têm combatido - o extermínio da ignorância" (Folha do Norte, n. 1272, p. 1).

Além disso, havia a certeza de que a carreira de mestra estava diretamente ligada à função materna, conforme é percebido no excerto:

[...] Z. soube acertadamente escolher a sua profissão. Nas aulas práticas eu fico em êxtase contemplando as maneiras delicadas com que sabe catequizar a infância! Que mestra perfeita vão ter os patriciozinhos do sertão ardente do nosso Brasil! Parece que ela depõe toda sua alma nas lições, nas observações, suavizando-as com uma carícia maternal (Folha do Norte, n. 1101, p. 02).

Como se vê, exigia-se da mulher-mestra, preparo para se tornar uma espécie de mãe de seus alunos, para que recebessem dela os ensinamentos que os capacitassem servir a 
pátria. Essa idéia estava presente no imaginário daquelas professoras e ligada ao projeto político do Brasil, desde a sua Independência. Neste aspecto, Pedro (1997, p. 293) afirma:

A idealização das mães estava presa à missão civilizadora das mulheres, a qual, de acordo com o ideário positivista, deveria ser instruída para aperfeiçoar o esposo e educar os filhos para a humanidade. Era justamente dentro dessa perspectiva que se defendia a educação feminina.

Assim, no ideário das professorandas figuravam sentimentos ligados à missão divina e quase sacerdotal, que deveria levar em consideração o traço da maternagem.

\subsection{Humildade e Modéstia}

Pertencente aos padrões da época, estão presentes os sentimentos de humildade e modéstia, contidos no conteúdo da maioria dos perfis. Neles, a auto-imagem não coloca os "dotes" intelectuais como qualidades, ao contrário, revela suas limitações.

Um dos perfis fala do sentimento que possuíam de si mesmas como intelectuais: "Reparem bem, amáveis leitores, e procurem ver nestas garatujas de má desenhista que sou, a nossa querida T." (Folha do Norte, $\mathrm{n}^{\circ} 1111$, p. 1).

Um outro perfil destaca: "Eis leitor o retrato em síntese da U., sem deixar de dar realce a sua principal qualidade que lhe é tão peculiar - a modéstia" (Folha do Norte, n. 1218, p. 1).

E ainda:

Assim é a U., como a humilde violeta que vive ocultada entre as suas folhas, assim vive a minha perfilada; mui retraída e simples, e ocultando sempre toda a sua bondade em uma grande modéstia (Jornal Folha do Norte, n. 1365, p. 02).

Expressar modéstia, no ato de escrever, poderia ser uma forma de estilo da época. Não obstante, os trechos que destacam esse atributo apontam uma das prerrogativas desejadas numa mestra naquele momento.

Quando as formandas falam de si revelam uma baixa auto-estima, quando estas mulheres não se reconheciam com capacidade intelectual elevada:

[...] Não vês no teu perfil o menor resquício de retórica que outra talvez pudesse te ofertar; nessa linguagem provida de um intelecto pobre, não deparas com uma frase sequer de elegância, porém em meu coração existe a beleza natural da sinceridade e em meu pensamento restará a lembrança dos felizes dias que passamos juntas (Folha do Norte, n. 1311, p. 1).

Ao invés da capacidade intelectual, destaca-se a nobreza de sentimentos, o que não corresponde a realidade, quando se coloca como ser de "intelecto pobre", visto que, os perfis demonstram que as professorandas apresentavam um intelecto de riquezas esboçadas nas descrições sobre as colegas. Entretanto, podemos apontar para um caminho sobre o ser e o representar-se no imaginário, o que pode significar que as mulheres, naquela época, tendiam a diminuir sua capacidade intelectual, pelo menos no que foi evidenciado nos perfis, na perspectiva de não transgredir valores e comportamentos delas exigidos pela sociedade. 


\section{Considerações Finais}

$\mathrm{Na}$ análise das fontes conhecemos um pouco dos valores e comportamentos das mulheres diplomadas pela Escola Normal de Feira de Santana, nas primeiras três décadas do século XX. Naqueles documentos vislumbramos um instantâneo das futuras mestras. Reconhecemos que não poderíamos resgatar de forma exata a sua identidade. Portanto, o que objetivamos foi o exercício de buscar compreender quem eram aquelas formandas e quais os sentimentos que as moveram na carreira do magistério.

Não obstante, a fragilidade esboçada pelas perfiladoras, o que percebemos no percurso da pesquisa é que essas mulheres foram destemidas e fortes, capazes de se embrenhar nos sertões, sem a companhia dos pais ou responsáveis, no intuito de realizar o que denominavam de missão: levar saber às crianças de todos os recantos do sertão baiano. Por isso, as denominamos de "Flores do Sertão", capazes de florescer em meio às adversidades que lhes foram oferecidas pela realidade onde exerceram seus papéis de mulheres e mestras.

\section{REFERÊNCIAS}

BEAUVOIR, Simone de. O segundo sexo: fatos e mitos. Trad. de Sérgio Milliet. Rio de Janeiro: Nova Fronteira, 1980.

BUTLER, Judith P. Sujeitos do sexo, gênero, desejo. In: BUTLER, Judith P. Problemas de Gênero: feminismo e subversão da identidade. Rio de Janeiro: Civilização Brasileira, 2003.

CIAMPA, Antonio da Costa. Identidade. In: Silvia T. M. Lane \& Wanderley Codo. (Orgs). Psicologia Social: o homem em movimento. São Paulo: Brasiliense, p. 58- 75.

D'INCAO, Maria Ângela. Mulher e família burguesa. IN: DEL PRIORI, Maria (org). $2^{\text {a }}$ ed. História das mulheres no Brasil. $2^{\text {a }}$ ed., São Paulo: Contexto, 1997.

ESCOLA Normal de Feira de Santana. Jornal Folha do Norte. 04 de junho de 1927, ano XVIII, n. 932.

ESCOLA Normal. Jornal folha do Norte. Feira de Santana, Bahia, 11 de Junho de 1927, ano XVIII, n. 933.

ESCOLA Normal de Feira de Santana: professores de 1930. Jornal Folha do Norte. Feira de Santana, Bahia, 23 de agosto de 1930, ano XXI, n. 1101.

ESCOLA Normal de Feira de Santana: professorandos de 1930. Jornal Folha do Norte. Feira de Santana, Bahia, 06 de setembro de 1930, ano XXI, n. 1103.

ESCOLA Normal de Feira de Santana. Jornal Folha do Norte. Feira de Santana, Bahia, ano XXV, 11.11.1933, n. 1269.

ESCOLA Normal de Feira de Santana. Jornal Folha do Norte. Feira de Santana, Bahia, ano XXV, 18.11.1933, n. 1270.

ESCOLA Normal de Feira de Santana. Jornal Folha do Norte. Feira de Santana, Bahia, ano XXV, 25.11.1933, n. 1271.

ESCOLA Normal de Feira de Santana. Jornal Folha do Norte. Feira de Santana, Bahia, ano XXV, 02.12.1933, n. 1272. 
ESCOLA Normal de Feira de Santana. Jornal Folha do Norte. Feira de Santana, Bahia, 25.08.1934, n. 1310.

ESCOLA Normal de Feira de Santana. Jornal Folha do Norte. Feira de Santana, Bahia, 01 de setembro de 1934, n. 1311.

ESCOLA Normal de Feira de Santana. Jornal Folha do Norte. Feira de Santana, Bahia, 15.09.1934, n. 1313.

ESCOLA Normal de Feira de Santana. Jornal Folha do Norte. Feira de Santana, Bahia, 22.08.1934, n. 1314.

ESCOLA Normal de Feira de Santana. Jornal Folha do Norte. Feira de Santana, Bahia, 03.11.1934, n. 1321.

ESCOLA Normal Rural de Feira de Santana. Jornal Folha do Norte. Feira de Santana, Bahia, 24.08.1935, n. 1362.

ESCOLA Normal da Feira: novos alfabetizadores da infância. Jornal Folha do Norte. Feira de Santana, Bahia, 31 de agosto de 1935, n. 1263.

ESCOLA Normal Rural da Feira. Jornal Folha do Norte. Feira de Santana, Bahia, 14.09.1935, 1365.

FORMATURA dos alunos: mestres de 1933 pela Escola Normal de Feira de Santana. Jornal Folha do Norte. Feira de Santana, Bahia, 16.12.1933, n. 1275.

GEERTZ, Clifford. A Interpretação das Culturas. Rio de Janeiro: Livro Técnico, 1989.

GRANADAS Feirenses. Jornal Folha do Norte. Feira de Santana, Bahia, ano XXII, 25 de outubro de 1930, 1110.

GRANADAS Feirenses. Jornal Folha do Norte. Feira de Santana, Bahia, ano XXII, 01.11.1930, n. 1111.

GRANADAS Feirenses. Jornal Folha do Norte. Feira de Santana, Bahia, ano XXIV, 19.11.1932, n. 1218.

GROSSI, Miriam Pillar. Masculinidade: uma revisão teoria. Antropologia Em Primeira Mão, Programa de Pós Graduação em Antropologia Social, Universidade Federal de Santa Catarina, n.1 (1995).

LOURO, Guacira Lopes. Mulheres na sala de aula. In: DEL PRIORI, Maria (org). $2^{\mathrm{a}}$ ed. História das mulheres no Brasil. $2^{a}$ ed., São Paulo: Contexto, 1997.

LOURO, Guacira Lopes. Gênero, sexualidade e educação: uma perspectiva pósestruturalista. 4.ed. Petrópolis: Vozes, 2001.

MOSCOVICI, Serge. Representações sociais: investigações em Psicologia Social. Petrópolis, RJ: Vozes.2003.

PESAVENTO, Sandra Jatahy. Em Busca de uma Outra História: Imaginando o

Imaginário. Revista Brasileira de História, São Paulo, Contexto, v. 15, no 29, 1995, pp. 927.

PASSOS, Elizete Silva. Palcos e platéias: as representações de gênero na faculdade de educação. Salvador: UFBA, 1999.

PEDRO, Joana Maria. In: DEL PRIORI, Maria (org). $2^{\text {a }}$ ed. História das mulheres no Brasil. $2^{a}$ ed., São Paulo: Contexto, 1997. 
SAFIOTTI, Heleieth Iara Bongiovanni. O poder do macho. São Paulo: Moderna, 1987.

SCOTT, Joan. Gênero: uma categoria útil de análise histórica. In: Revista Educação e Realidade, v. 2, n. 16. Porto Alegre, 1990.

SOUSA, Sandra M. N. Sexo e Gênero: considerações e delimitação de eixos da identidade, do desejo e do prazer. Revista Pós Ciências Sociais. v.2 n.3 jan/jul, São Luis, MA, 2005. Disponível em: <http://www.pgcs.ufma.br/Revista\%20UFMA/n3/n3_Sandra_Sousa.htm> Acesso em: $30 / 05 / 2009$

STIGGER, Marco Paulo; WENETZ, Ileana. A construção do gênero no espaço escolar. Movimento. Porto Alegre, v.12, n. 01, p. 31-58, janeiro/abril de 2006.

${ }^{11}$ Doutor em Educação pela Universidade Federal da Bahia; Professor Adjunto da Matéria História da Educação.

${ }^{2}$ PhD Université de Sherbrooke, U.S., Canadá. Pós-Doutorado, Universidade do Vale do Rio dos Sinos, UNISINOS, Brasil; Professora Titular da Matéria Didática.

${ }^{3}$ Fonte: Jornal Folha do Norte, n. 1116, p. 1.

${ }^{4}$ Anexado à Escola Normal e teve seu prédio ocupado por ela.

${ }^{5}$ Localizado na Rua Direita, atual Rua Conselheiro Franco, onde funciona atualmente o Centro Universitário de Cultura de Arte, órgão ligado à Universidade Estadual de Feira de Santana.

${ }^{6}$ Livro de Atas da Congregação da Escola Normal de Feira de Santana, 01.06.1927, p. 01.

${ }^{7}$ Livro de Ata da Congregação da Escola Normal de Feira de Santana, Ata de Inauguração, em 01.06.1927, p. 01-02.

Artigo recebido em: 14/08/09

Aprovado para publicação em: 29/01/10 